\title{
Review \\ Smartphone-Based Visual Inspection with Acetic Acid: An Innovative Tool to Improve Cervical Cancer Screening in Low-Resource Setting
}

\author{
Jana Sami ${ }^{1, *,+}$, Sophie Lemoupa Makajio ${ }^{1,2,+}{ }^{\text {, Emilien Jeannot }}{ }^{3,4} \mathbb{D}$, Bruno Kenfack ${ }^{5}$, Roser Viñals ${ }^{6} \mathbb{D}$, \\ Pierre Vassilakos ${ }^{1,7}$ (D) and Patrick Petignat ${ }^{1}$ (D)
}

check for

updates

Citation: Sami, J.; Lemoupa Makajio, S.; Jeannot, E.; Kenfack, B.; Viñals, R.; Vassilakos, P.; Petignat, P. Smartphone-Based Visual Inspection with Acetic Acid: An Innovative Tool to Improve Cervical Cancer Screening in Low-Resource Setting. Healthcare 2022, 10, 391. https:// doi.org/10.3390/healthcare10020391

Academic Editor: Stefano Restaino

Received: 30 December 2021

Accepted: 11 February 2022

Published: 18 February 2022

Publisher's Note: MDPI stays neutral with regard to jurisdictional claims in published maps and institutional affiliations.

Copyright: (C) 2022 by the authors. Licensee MDPI, Basel, Switzerland. This article is an open access article distributed under the terms and conditions of the Creative Commons Attribution (CC BY) license (https:// creativecommons.org/licenses/by/ $4.0 /)$.
1 Department of Pediatrics, Gynecology and Obstetrics, Geneva University Hospitals, 1205 Geneva, Switzerland; lemoupasophie@yahoo.fr (S.L.M.); pierrevassilakos@bluewin.ch (P.V.); patrick.petignat@hcuge.ch (P.P.)

2 Bafoussam Regional Hospital, Bafoussam FCQ5+X4, Cameroon

3 Institute of Global Health, Faculty of Medicine, 1211 Geneva, Switzerland; emilien.jeannot@unige.ch

4 Addiction Medicine Service, Lausanne University Hospital (CHUV), 1011 Lausanne, Switzerland

5 Department of Gynecology-Obstetrics, Faculty of Medicine and Pharmaceutical Sciences,

University of Dschang, Dschang C2WW+4M, Cameroon; brunokenfack@gmail.com

6 Signal Processing Laboratory (LTS5), École Polytechnique Fédérale de Lausanne (EPFL), 1015 Lausanne, Switzerland; roser.vinalsterres@epfl.ch

7 Geneva Foundation for Medical Education and Research, 1202 Geneva, Switzerland

* Correspondence: samijana04@gmail.com

+ These authors contributed equally to this work.

\begin{abstract}
Visual inspection with acetic acid (VIA) is recommended by the World Health Organization for primary cervical cancer screening or triage of human papillomavirus-positive women living in low-resource settings. Nonetheless, traditional VIA with the naked-eye is associated with large variabilities in the detection of pre-cancer and with a lack of quality control. Digital-VIA (D-VIA), using high definition cameras, allows magnification and zooming on transformation zones and suspicious cervical regions, as well as simultaneously compare native and post-VIA images in realtime. We searched MEDLINE and LILACS between January 2015 and November 2021 for relevant studies conducted in low-resource settings using a smartphone device for D-VIA. The aim of this review was to provide an evaluation on available data for smartphone use in low-resource settings in the context of D-VIA-based cervical cancer screenings. The available results to date show that the quality of D-VIA images is satisfactory and enables CIN1/CIN2+ diagnosis, and that a smartphone is a promising tool for cervical cancer screening monitoring and for on- and off-site supervision, and training. The use of artificial intelligence algorithms could soon allow automated and accurate cervical lesion detection.
\end{abstract}

Keywords: cervical cancer screening; low and middle-income countries; training; VIA/VILI; smartphonebased; digital colposcopy; artificial intelligence

\section{Introduction}

Cervical cancer (CC) is one of the most common cancers in women and one of the leading causes of cancer death in women in developing countries, although it is almost a totally preventable cancer. In 2020, more than 600,000 new cases of cervical cancer were reported worldwide [1]. To reduce the burden of disease, the World Health Organization (WHO) has launched a global program to eliminate cervical cancer, with the following targets: (i) all countries have to achieve $90 \%$ vaccination coverage, (ii) $70 \%$ of screening coverage, and (iii) $90 \%$ access to treatment for cervical pre-cancer or cancer [2]. 
To reach the second and third WHO targets, towards cervical cancer elimination, women should be screened using high-performance tests between the ages of 5 to 45 years old, coupled with treatment, if required [3]. Visual assessment of the cervix with acetic acid (VIA) has been adopted by the WHO in primary screenings or in the triage of HPV-positive women as an affordable and adapted method in low-resource settings [3]. However, "nakedeye" VIA assessment remains a highly subjective test with low performance and limited quality control [4]. Limitations were first inherent to the technique itself, but variations of training, mentorship, and supervision may also account for the performance difference observed across studies.

To provide easier recognition of cervical intraepithelial neoplasia (CIN) by screeners, digital cervical pictures taken during VIA (D-VIA) with a camera have progressively developed and are being adopted by many with encouraging results $[5,6]$. However, picture acquisition has not been so easy to perform; in particular, good image quality, managing difficulties (e.g., focusing), and adequate light sources have been challenging.

To effectively evaluate the cervix before and after acetic acid application, light and magnification are needed, which can be easily and adequately obtained with a smartphone device. Smartphones can assist screeners in determining morphology, localization, and the type of transitional zone, and distribution of aceto-whitening features. Implementing smartphone D-VIA has opened up a new dimension to VIA and may be a major improvement in cervical cancer prevention. Furthermore, the increasing prevalence of smartphone-use in low-resource settings makes it an ideal low cost device. Research teams and engineers have developed programs to increase accuracy of D-VIA diagnosis from smartphone pictures. Our aim was to provide an overview of the data available on smartphone-use for cervical cancer screening in low-resource settings and describe its promises and challenges.

\section{Methodology}

A literature search was conducted on MEDLINE and LILACS, selecting Englishand French-written studies published between January 2015 and November 2021. Terms used for research were: (cervical cancer screening) and ((smartphone) or (digital colposcopy)). Articles were excluded from the title, abstract, and/or methodology: (i) if they had not been conducted in a cervical cancer screening context using D-VIA, (ii) if they did not include the use of smartphones for D-VIA image acquisition, (iii) if the study was not conducted in a low-resource setting or low and middle income countries (LMICs), and (iv) if the study data were not published in full articles. Specific MeSH terms (VIA, D-VIA, LMICs) were voluntarily not used because it limited greatly the number of results. Research period was chosen arbitrarily to overview most recent data. We also summarized the articles published on artificial intelligence (AI) according to our research for cervical pre-cancer identification. These studies were not necessarily conducted in low-resource settings considering that AI could be used in the near future in LMICs (Figure 1). Reference lists of identified papers were also reviewed to ensure that all studies meeting our inclusion criteria were considered. Two reviewers independently assessed each article for eligibility. 


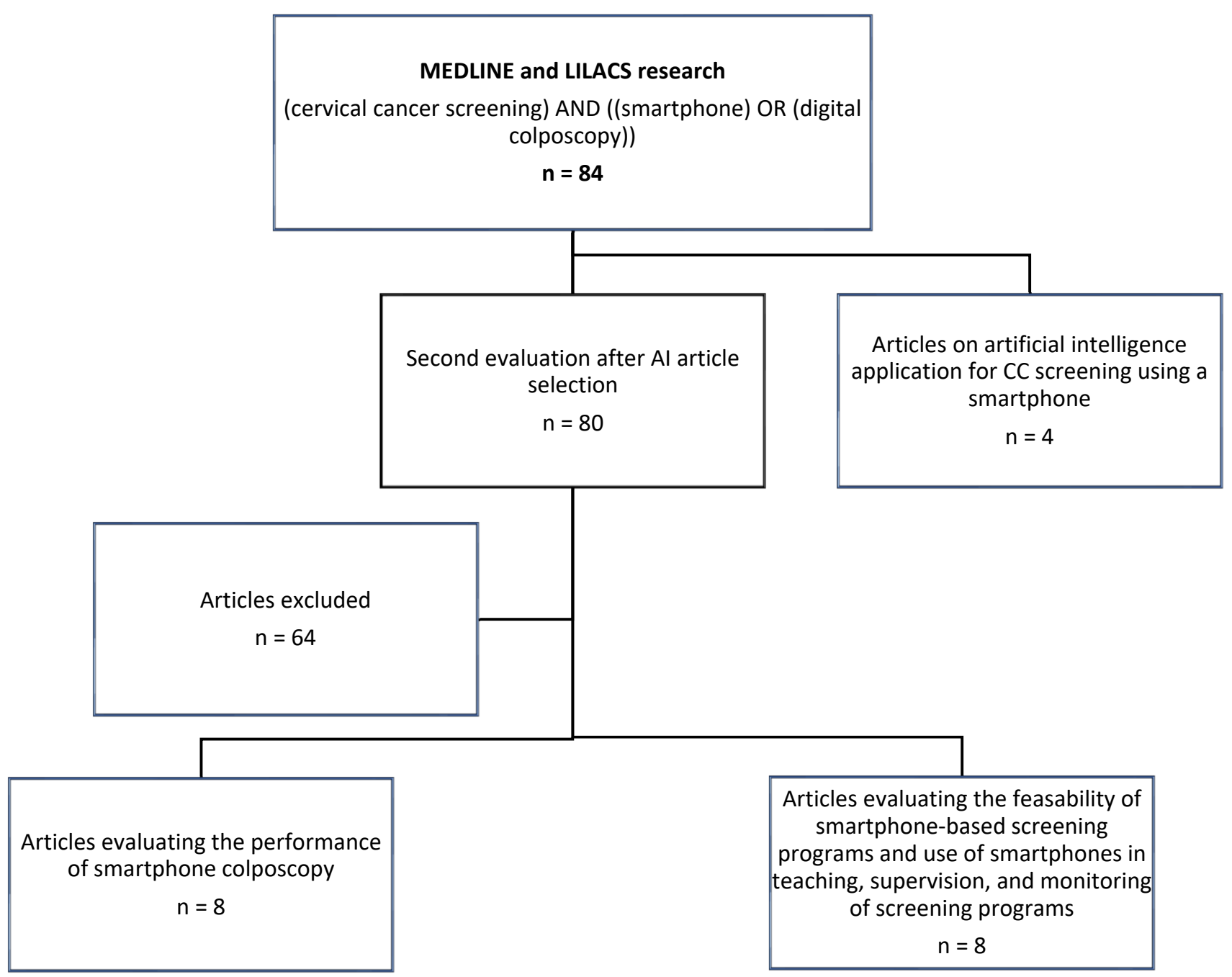

Figure 1. Flowchart of articles selection.

\section{Visual Inspection with Acetic Acid (VIA): Strengths and Limitations}

VIA is a procedure in which a healthcare provider applies a solution of 3 to $5 \%$ acetic acid with the aim of highlighting and identifying CIN. The procedure requires an experienced screener able to conduct a naked-eye examination and interpret the cervical change before and after application of acetic acid. VIA interpretation is crucial for determining if the screen is positive or negative and to decide the strategy of treatment, if positive. The decision to treat relies on the provider's evaluation and experience; false positive cases may lead to overtreatment while false negatives will lead to misdiagnosis. If the screen is positive and if treatment is required, the provider must decide if the condition is eligible for ablative treatment (thermal ablation or cryotherapy) or excisional treatment (i.e., large loop excision of the transformation zone (LLETZ)) or referral to multimodal therapy in case of suspicion of invasive cancer. The main strength of the VIA approach is that it is affordable and offers the possibility of immediate results and treatment in a single visit.

Since the end of the 1990s, some countries have endorsed VIA instead of cytology as a primary screening in their national cervical cancer control programs, linking in the same visit screenings and treatments [7]. However, the technique is considered by some as a low standard of care, with critical weaknesses, such as its subjectivity, which leads to high variability in the provider's performance as well as a lack of validated quality assurance [8].

Mustafa et al. conducted a systematic review to compare the accuracy of an HPV test, cytology (cervical smear), unaided VIA, and a colposcopy for cervical cancer screening in high-income countries. Results showed a pooled sensitivity of $69 \%$ (CI 95\% 54-81) for 
VIA compared to 95\% (CI 95\% 84-98) for HPV testing; and a specificity of $87 \%$ (CI 95\% 79-92) for VIA compared to 84\% (CI 95\% 72-91) for HPV. When compared to cervical smear accuracy, VIA caused a significant increase in overtreatment with 58 more false positives for 1000 women [9]. These weaknesses might explain the absence of implementation of VIAbased screening programs more than 20 years after publication of the WHO guidelines [10]. Despite the existence of recommendations and important investments made by private and public organizations in the field, difficulties have occurred with implementation of the Sub-Saharan cervical screening program [11]. This is of great concern, as the likelihood of reducing the incidence of cervical cancer relies on an effective and inexpensive screening method and a well-organized program.

\section{VIA-Enhanced with Digital Imaging}

The advent of digital cervical photography after acetic application (D-VIA), taken by on-site healthcare providers with cameras in order to assist the CIN identification was an important step in cervical cancer screenings [12]. A study evaluating cervical digital photography and colposcopy by different observers reported an agreement in $89.9 \%$ of the cases (kappa $(\mathrm{k})=0.588)$, a higher sensitivity $(52.5 \%)$, and positive predictive value (PPV) $(60 \%)$ as compared to colposcopy ( $35 \%$ and $48.28 \%$, respectively). Specificity $(91.8 \%$ vs. $91.2 \%)$, negative predictive value (NPV) $(89.3 \%$ vs. $85.8 \%)$, and diagnostic accuracy $(84.4 \%$ vs. $80.7 \%)$ were quite similar. This study supports that cervical digital photography may be an alternative to colposcopy for CIN diagnosis [13]. In Zambia and Kenya, cervix digital images were taken by a camera and it was reported difficult to capture images and retain details without distortion (fluctuation in color, not enough light intensity, loss of resolution) $[14,15]$. Ensuring image quality (color accuracy, focus) with a camera is a challenging issue.

Alternatively, smartphones, which are often combined with auxiliary lenses (i.e., MobileODT), allowing the acquisition of high-resolution cervical images, enable visualization of morphological features, which may be difficult to see with naked-eye alone [16]. Advantages of a smartphone over a traditional camera is its ease of use, it does not need an external light source, and it allows easy zooming and comparisons of different pictures taken during an exam (native, VIA). D-VIA seems to have a higher discriminative power when compared to a naked-eye examination in detecting precancerous lesions; thus, making it an additive value to traditional VIAs to improve the diagnosis of cervical precancerous lesions.

\section{Performance for CIN2+ Diagnosis}

Image quality for cervical intraepithelial neoplasia (CIN) detection relies on the quality of the digital technology used, as well as on image classification and registration. Currently, there is no standard specific recommendation similar to what exists in other medical specialties (i.e., digital imaging and communication in medicine (DICOM)).

In Madagascar, Gallay et al. evaluated the quality of smartphone images to assess feasibility and usability of a mobile application in low-resource settings. Women aged 30-65 years old were recruited in a cervical cancer screening campaign and HPV-positive ones underwent VIA assessment [17]. Pictures were taken using a Samsung Galaxy S5 and a phone application called "Exam" was used to classify images. A total of 208 consecutive pictures were assessed by observers and quality was judged as adequate for diagnoses in $93.3 \%$ of cases.

Tran et al. reported a sensitivity of $71.3 \%$ (95\% CI 67-75.7) and a specificity of $62.4 \%$ (95\% CI 57.5-67.4) for CIN2+ detection from D-VIA images taken by smartphones-a Samsung Galaxy S4 and S5-in Madagascar and evaluated by off-site gynecologists [18].

Studies that evaluated these issues, with or without image management applications, support that the quality of the image was, most of the time, considered sufficient for diagnosis and the decision of treatment. However, current evidence regarding the use and benefits regarding implementation of digital-VIA for CIN2+ diagnosis is still weak, as there are no randomized controlled trials (VIA versus D-VIA) or large prospective studies 
that have evaluated this issue. Results show overall good specificity for D-VIA; sensitivity values are however heterogeneous (Table 1).

Table 1. Studies evaluating the performance of a digital colposcopy using a smartphone for cervical cancer screening in LMIC.

\begin{tabular}{|c|c|c|c|c|}
\hline Study & Population & Intervention and Device & Outcome and Results & Strengths and Weaknesses \\
\hline $\begin{array}{l}\text { Mungo } \\
\text { et al., } 2021 \\
{[19]}\end{array}$ & $\begin{array}{l}\text { Western } \\
\text { Kenya } \\
25-49 \text { y } \\
\text { HIV-positive } \\
n=164 *\end{array}$ & $\begin{array}{l}\text { D-VIA images taken by } \\
\text { nonphysicians. } \\
\text { Samsung J8; } \\
\text { three off-site expert } \\
\text { colposcopists } \\
\text { assessed images. }\end{array}$ & $\begin{array}{l}\text { Outcome: performance to detect } \\
\text { CIN2+ (off-site) and } \\
\text { acceptability of D-VIA. } \\
\text { Results: } \\
\text { Se ranging from } 21.4 \% \text { ( } 95 \% \text { CI, } \\
0.06 \text { to } 0.43) \text { to } 35.7 \%(95 \% \text { CI, } \\
0.26 \text { to } 0.46) \text {. } \\
\text { Sp between } 85.5 \% \text { (95\% CI, } 0.81 \\
\text { to } 0.90) \text { to } 94.9 \% \text { ( } 95 \% \text { CI, } 0.92 \text { to } \\
0.98) \text {. } \\
99.4 \% \text { of women were } \\
\text { comfortable with the use of } \\
\text { a smartphone. }\end{array}$ & $\begin{array}{l}\text { Comment: low sensitivity, very } \\
\text { good acceptability. } \\
\text { Strengths: histology as } \\
\text { reference standard. } \\
\text { Limitations: HIV population. }\end{array}$ \\
\hline
\end{tabular}

Goldstein

[20] et al., 2019
China (rural Yunnan areas) $35-65$ y $n=216^{*}$
VIA and digital images. Samsung Galaxy J5 Pro (mobile ODT system).
Outcome: performance to detect CIN1 and CIN2+ Results: Se: NR, Sp: NR.
Comment: accuracy of D-VIA to differentiate between CIN1 and CIN2+

Strengths: histology as reference standard.

Limitations: low observed prevalence of HPV (6\%), small number of CIN2+ $(n=15)$.

Comment: accuracy of D-VIA to differentiate between CIN1 and CIN2+.
Cambodia VIA and digital images. 30-49 y Samsung Galaxy J5 Pro

Thay et al., $\quad n=250$ $=56^{* *}$ 2019 [21] HPV-positive
Outcome: differentiation between CIN1 and CIN2+. Results: Se: NR, Sp: NR.
Strengths: histology as reference standard (but only in case of CIN2+ suspicion). Limitations: study setting in an urban hospital, results might not be applicable to rural regions, few CIN2+ lesion $(n=4)$.

Comment: visual assessment demonstrated relatively high Se. Strengths: histology as reference standard. Limitations: small sample size (19 CIN2+).

Outcome: performance to detect CIN2+.

Results: Se 71.3\% (95\% CI 67-75.7); Sp 62.4\% (95\% CI 57.5-67.4)

Smartphone Galaxy S4/S5.

Four clinicians assessed D-VIA images and classified them in an app called "Exam". Smartphone Galaxy S4/S5.
Outcome: evaluation of image quality and inter-observer agreement.

Results: adequate quality for visual assessment in $93.3 \%$ of cases. Moderate inter-observer agreement, with kappa value $=0.45(0.23-0.56)$.
Comment: small study, designed only for quality of images. Limitations: no histology for diagnosis confirmation. 
Table 1. Cont.

\begin{tabular}{|c|c|c|c|c|}
\hline Study & Population & Intervention and Device & Outcome and Results & Strengths and Weaknesses \\
\hline $\begin{array}{l}\text { Urner et al., } \\
2017 \text { [22] }\end{array}$ & $\begin{array}{l}\text { Madagascar } \\
30-69 y \\
n=187 *\end{array}$ & $\begin{array}{l}\text { Fifteen clinician } \\
\text { evaluated D-VIA images } \\
\text { (off-site). } \\
\text { Samsung Galaxy S4/S5. }\end{array}$ & $\begin{array}{l}\text { Outcome: performance in the } \\
\text { detection of CIN2+. } \\
\text { Results: Se } 94.1 \%(95 \% \mathrm{CI} \\
\text { 81.6-98.3); Sp } 50.4 \% \text { (95\%CI } \\
\text { 35.9-64.8). }\end{array}$ & $\begin{array}{l}\text { Comment: Se to detect CIN2+ } \\
\text { lesion better than } \\
\text { generally reported. } \\
\text { Strengths: histology as reference. } \\
\text { Limitations: small sample size } \\
\text { and limited number of CIN2+ } \\
(n=14) .\end{array}$ \\
\hline
\end{tabular}

Outcome: performance to detect

\section{CIN2+ and}

inter-observer agreement.

Comparison of VIA

Catarino Madagascar (on-site) and D-VIA

et al., 2015 30-65 y (off-site).

[23] $n=137$ *
Samsung Galaxy S4/S5.
Results on-sites: Se $66.7 \%$

(95\%CI 30-90.3); Sp 85.7\%

(95\%CI 76.7-91.6).

Results off-site: Se 66.7\% (95\%CI

30-90.3); Sp 82.3\%

(95\%CI72.4-89.1).

Moderate to poor inter-observer

agreement: kappa 0.28 .
Comment: higher Sp than generally reported, demonstration that off-site assessment is feasible.

Strengths: histology as reference Limitations: $30.7 \%$ drop-out rate, small sample size
Outcome: performance to detect CIN 2+.

Results on-site: Se $28.6 \%$ (95\%CI $3.7-71 \%)$,

Sp 87.2\% (95\%CI 77.7-93.7\%). Results off-site: Se ranging from 42.9 (95\%CI 9.9-81.6) to $85.7 \%$ (95\%CI 42.1-99.6); Sp from 48.1 (95\% CI 38.5-59.7) to $79.2 \%$ (95\%CI 68.5-87.6).
Comment; Off-site assessment feasible, lower Se for on-site assessment than reported in literature.

Strengths: histology as reference. Limitations: $27.9 \%$ drop-out rate, small sample size $\begin{array}{ll}\text { et al., } 2015 & 30-65 \mathrm{y} \\ & n=122\end{array}$

[16]
D-VIA (on-site) and

D-VIA (off-site).

Samsung Galaxy S4.

Abbreviations: CIN (cervical intraepithelial neoplasia), DC (digital colposcopy), D-VIA (smartphone-based visual inspection with acetic acid), D-VILI (smartphone-based visual inspection with Lugol iodine), ECC (Endocervical curettage), HPV-Hr (human papilloma virus-high risk), HPV-positive (human papilloma virus positive), NR (not reported), Se (sensitivity), Sp (specificity), y (years old). * All HPV-positive; ** 56/250 women were HPV-positive.

\section{On-Site Training and Supervision}

Current understanding of a VIA-based approach supports that the method needs to be conducted with adequate training, supervision, and quality control to optimize the technique [8]. In a "screen and treat" strategy, frontline screeners play key roles and supervision is important, but it may not be available in healthcare centers located in remote areas [24]. Production of digital images allow to have records of the appearance of the cervix before and after acetic acid application, which permits screeners and supervisors to review the selected cases for quality control.

Asgary et al. explored the acceptability and feasibility of smartphone-based training of Ghanaian healthcare professionals using VIA and D-VIA. Community health nurses completed a two-week on-site introductory training, followed by ongoing, three-month text messaging, supported by a VIA reviewer. Smartphone-based training and mentorship were perceived by providers as important and essential complementary processes to further develop diagnostic and management competencies [25]. In semi-rural Tanzania, five providers were trained to perform smartphone-enhanced VIA with real-time trainees supported by regional experts. Images were sent through smartphone applications on the available mobile telephone networks. Within one month of training, the agreement rate between trainees and expert reviewers was 96.8\% [26]. Maintaining competencies and accuracies of VIA are also major challenges as the standard short-term onsite VIA trainings may not guarantee skills retention. VIA web-based trainings appear to be tools that can be used for continuous education, to maintain frontline healthcare providers' skills, which will eventually contribute to a higher diagnosis performance [27,28] (Table 2). 
Table 2. Studies evaluating feasibility of smartphone-based screening program in LMICs, staff training, and on/off-site supervision.

\begin{tabular}{llll}
\hline Studies & Population & Intervention & Results, Comment \\
\hline & Eswatini & Smartphone-based VIA screening & Results: agreement 100\% for positive \\
Asgary et al., & $25-49$ y & $n=247$ & $\begin{array}{l}\text { program, standard VIA training, } \\
\text { cases and 95.7\% for negative; kappa 0.74, } \\
\text { then 0.64 after } 3 \text { months and 0.79 after }\end{array}$ \\
& HPV status = NR & $\begin{array}{l}\text { refresher course, and 6-month } \\
\text { mHealth mentorship. }\end{array}$ & 6 months,
\end{tabular}

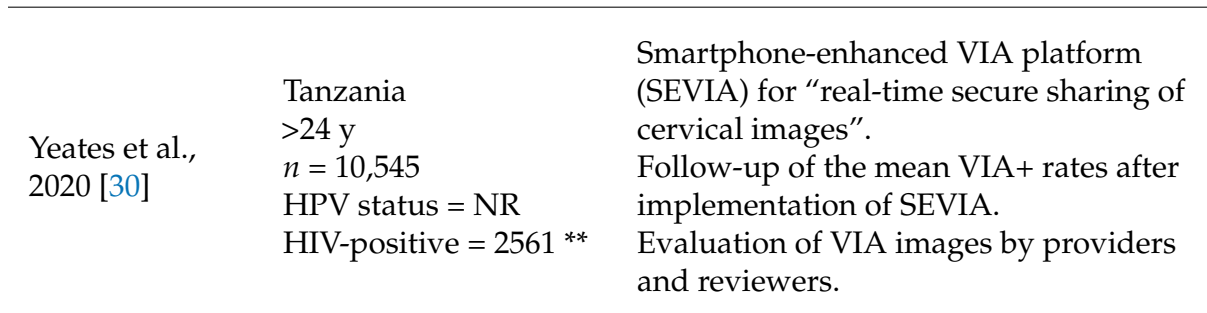

$\begin{array}{lll} & \text { Ghana } & \text { Providers' perceptions and experiences: } \\ \text { Asgary et al., } & \text { mean age }=33.8 \mathrm{y} & 15 \text { nurses, } 1 \text { nurse supervisor, } 1 \\ 2019[25] & n=21 & \text { expert reviewer. }\end{array}$

$\begin{array}{lll} & \text { Madagascar } & \text { Registration of cervical cancer screening } \\ \text { Quercia et al., } & 30-65 \mathrm{y} & \text { program data onto a secure web-based } \\ 2018[31] & n=151 & \text { platform, for monitoring purposes. } \\ & \text { HPV status }=\text { NR } & \text { Quality of data evaluation. }\end{array}$

$\begin{array}{ll} & \text { India } \\ \text { Sharma et al., } & \text { Mean age }=38.79 \text { y } \\ 2018[32] & n=180 \\ & \text { HPV status }=\text { NR }\end{array}$

Assessment of nurses' judgment for diagnosis of cervical pre-cancerous lesions using smartphone images.

Results: VIA+ rates increased from 4 to $6.2 \%$ after implementation of SEVIA. Provider-Reviewer concordance rate $=90 \%$ over the 1 -year period. Comment: SEVIA allows enhanced quality of visual inspection, training, real-time data acquisition, monitoring, and evaluation.

Comment: cervical images provided peer-to-peer learning opportunities, better trust of patients, targeted education, and improvement of adherence, as well as implementation of quality control.

Results: less than $0.02 \%$ of key data missing.

Comment: small group. Helps for real-time monitoring, but impact on women follow-up not assessed.

Results: moderate nurse-expert
agreement, kappa 0.45 .
Comment: appropriately trained nurses
can reliably conduct screening. Real-time
expert feedback might
improve reporting.

Providers completed a 2-week on-site

$\begin{array}{ll} & \text { Ghana } \\ \text { Asgary et al., } & 25-45 \mathrm{y} \\ \text { 2016 [33] } & n=169 \\ & \text { HPV status = NR }\end{array}$
training in VIA, followed by a 3-month VIA training supported by text messaging by an expert reviewer (real-time feedback). Comparison of agreement rates for VIA+.

Results: total agreement rate, 95\%, average agreement rate between each provider and expert reviewer $89.6 \%$. Kappa 0.67

\section{Results: $12.6 \%$ pre-cancerous lesions,} $0.7 \%$ suspected cancer.

Kenya Training of providers using pictures

Peterson et al., Age $=$ NR

2016 [34] $\quad n=824$

HPV status $=$ NR taken.

Decision support "Job Aid tool" included in the mobile application (MobileODT system) for diagnosis and treatment.
Comment: deployment of the "EVA

System" allows monitoring of clinical decisions made by nurses.

Help of "Job Aid" decision support for treatment and gives more confidence to providers.

Feasibility of smartphone camera to perform "Enhanced VIA" and level of agreement between trainee and expert over time (agreement 96.8\%), Response timing (real-time), $1-5 \mathrm{~min} 48.4 \%$ and $<10 \mathrm{~min} 60 \%$ of the time.

$\begin{array}{ll} & \text { Tanzania } \\ \text { Yeates et al., } & 25-49 \text { y } \\ \text { 2016 [26] } & n=1072 \\ & \text { HPV status = NR }\end{array}$

Training providers to perform D-VIA with real-time support from regional experts, images sent through a smartphone application. 


\section{Off-Site Mentorship}

The use of D-VIA enables screeners from remote areas to send cervix images to a more experienced supervisor, ensuring a quality assurance system. Recent studies showed that off-site detection of cervical lesions based on evaluation of smartphone photographs is feasible in a low-resource context and seems to be as reliable as an on-site diagnosis [22,23]. D-VIA based on cellphone screening allows communication between frontline healthcare providers working in remote clinics and experts located in urban area, thereby allowing support and concertation between physicians. In Tanzania, a project that is currently underway, "The Kilimanjaro Cervical Screening Project", in which healthcare workers perform screenings by VIA and send images through their mobile phones for confidential, prompt, expert consultations, open up new dimensions to the VIA approach. Coupling smartphones to VIA can be of significant contributions in improving quality work and reducing patients' waiting time and loss of follow-up [26]. (Tables 1 and 2).

In Cameroon, the Extension for Community Health Outcome (ECHO) telementoring scheme was implemented to provide support to nurses running the Women's Health Program of the Baptist Health Services [35]. It is a program run by trained nurses to provide lower-cost cervical cancer screenings and treatments. During meetings using the ECHO model, specialists from the USA, Canada, Europe, and Africa have reviewed clinical cases presented by front line nurses and provided tailored didactic lectures. This approach is highly appreciated by frontline providers for the opportunity to learn with peers. They reported that $\mathrm{ECHO}$ sessions increased their ability to access specialty care.

\section{Data Registration and Monitoring}

Important advantages of D-VIA include the following: it allows storing patients' cervical images and data on online databased, which facilitates communication between health professionals, during patient follow-ups, and prevents the loss of information. In Madagascar, a digitalized patient record, the Cervical Cancer Prevention System (CCPS), was developed. It is a mobile health application that allows registration of clinical data, which can be transmitted onto a secure, web-based platform using an internet connection [31]. Healthcare providers have access to the central database and can use it for follow-up visits. In rural India, Bhatt et al. showed the use of a mobile health system as a key component for cervical and oral cancer screenings [36]. Data were entered manually and the application contained permission checks to minimize the risks of "personal-identifying" data security breaches. Peterson et al. showed that the EVA system, consisting of "a mobile colposcope built around a smartphone" with "an online image portal for storing and annotating images", could monitor real-time screening data and identify positive patients to organize treatments when required [34] (Table 2).

\section{Artificial Intelligence: A Vision of the Future}

Artificial intelligence (AI) is revolutionizing medical diagnoses, and applications in the field of cervical cancer screening have demonstrated that it can achieve higher diagnostic accuracies than experts [37,38]. Most AI tools for cervical cancer screenings have been developed using images taken by standard colposcopes [39-42]. Nevertheless, colposcopes are rarely available in low-resource settings and, therefore, AI models are being developed using images captured by other acquisition devices more adequate for limited resource contexts. In particular, smartphones are used as acquisition devices for the development of algorithms, with advantages described above.

Mobile ODT uses smartphones with optical lenses attached to acquire images and their databases are used to develop classification algorithms, such as in [43], proving the potential of using smartphones as acquisition devices for developing automatic diagnosis tools. Kudva et al. used an android device with a camera to develop AI classification tools, achieving very high performances [44]. Bae et al. developed a smartphone-based endoscope that acquires and classifies images before and after application of the acetic acid [45]. Finally, Viñals et al. developed an AI algorithm based on smartphone images 
without any additional component [46]. In the near future, smartphone mHealth and automated visual evaluations may allow for the automated and accurate detections of CIN and become key elements in cervical cancer screenings. (Table 3)

Table 3. Articles on artificial intelligence application for CC screening.

\begin{tabular}{|c|c|c|c|c|c|}
\hline Studies & Population & Objective & Device & Intervention & Results \\
\hline $\begin{array}{l}\text { Kudva } \\
\text { et al., } 2018 \\
{[44]}\end{array}$ & $\begin{array}{l}\text { India } \\
>24 \mathrm{y} \\
n=102\end{array}$ & $\begin{array}{l}\text { Develop a decision support system } \\
\text { for cervical cancer screening with an } \\
\text { inbuilt image processing algorithm. }\end{array}$ & $\begin{array}{l}\text { Android device } \\
\text { with a camera } \\
\text { of } 13 \mathrm{Mpx} \text {. }\end{array}$ & $\begin{array}{l}102 \text { images } \\
\text { Reference }=\text { expert } \\
\text { evaluation. }\end{array}$ & $\begin{array}{l}\text { Accuracy } 97.9 \%, \\
\text { Se } 99.0 \% \text {, Sp } 97.1 \% \text {, } \\
\text { AUC NR. }\end{array}$ \\
\hline $\begin{array}{l}\text { Bae et al., } \\
2020 \text { [45] }\end{array}$ & $\begin{array}{l}\text { South } \\
\text { Korea, } \\
>20 \mathrm{y} \\
n=20\end{array}$ & $\begin{array}{l}\text { Develop a new cervical cancer } \\
\text { screening technique and implement a } \\
\text { machine-learning algorithm using } \\
\text { images taken during VIA with a } \\
\text { smartphone-based endoscope. }\end{array}$ & $\begin{array}{l}\text { Smartphone- } \\
\text { based } \\
\text { endoscope. }\end{array}$ & $\begin{array}{l}40 \text { images ( } 2 \text { per } \\
\text { patient). } \\
\text { Expert evaluation } \\
\text { vs AI. } \\
\text { Reference = } \\
\text { histopathology. }\end{array}$ & $\begin{array}{l}\text { Accuracy } 78.3 \% \text {, } \\
\text { Se } 75.8 \%, \text { Sp } 80.3 \% \text {, } \\
\text { AUC } 0.805 . \\
\text { Clinicians' mean } \\
\text { accuracy } 77.5 \% \text {, } \\
\text { Se } 62.5 \%, \text { Sp } 100 \% \text {, } \\
\text { AUC NR. }\end{array}$ \\
\hline $\begin{array}{l}\text { Xue Z. } \\
\text { et al., } 2020 \\
{[43]}\end{array}$ & $\begin{array}{l}\text { Various } \\
\text { countries } \\
>18 \mathrm{y} \\
n=3221\end{array}$ & $\begin{array}{l}\text { Evaluate accuracy of automated } \\
\text { visual evaluation (AVE) on } \\
\text { smartphone images. }\end{array}$ & $\begin{array}{l}\text { MobileODT } \\
\text { system } \\
\text { (smartphone } \\
\text { with lens). }\end{array}$ & $\begin{array}{l}7587 \text { images. } \\
\text { Reference }=\text { expert } \\
\text { evaluation }\end{array}$ & $\begin{array}{l}\text { Accuracy NR, } \\
\text { Se NR, Sp NR, } \\
\text { AUC 0.87 (95\% CI } \\
0.81-0.92)\end{array}$ \\
\hline $\begin{array}{l}\text { Viñals et al., } \\
2021 \text { [46] }\end{array}$ & $\begin{array}{l}\text { Cameroon, } \\
\text { Switzerland } \\
30-49 \text { y } \\
n=44\end{array}$ & $\begin{array}{l}\text { Development of a smartphone-based } \\
\text { algorithm to detect cervical precancer } \\
\text { from the dynamic features (dynamics } \\
\text { of aceto-whitening). }\end{array}$ & $\begin{array}{l}\text { Samsung } \\
\text { Galaxy S5 }\end{array}$ & $\begin{array}{l}44 \text { dynamic } \\
\text { images; } \\
\text { Expert evaluation } \\
\text { vs. AI. } \\
\text { Reference = } \\
\text { histology }\end{array}$ & $\begin{array}{l}\text { AI accuracy } 89 \% \text {, } \\
\text { Se } 90 \%, \text { Sp } 87 \% \text {, } \\
\text { AUC NR. } \\
\text { Clinicians' mean } \\
\text { accuracy } 71 \% \text {, } \\
\text { Se } 68 \%, \text { Sp } 78 \% \text {, } \\
\text { AUC NR. }\end{array}$ \\
\hline
\end{tabular}

Abbreviations: AI (artificial intelligence), AUC (area under the curve), Mpx (megapixels), NR (not reported), Se (sensitivity), Sp (specificity), VIA (visual inspection with acetic acid).

\section{Conclusions and Perspective}

Concerns about data protection are sometimes addressed when it comes to smartphoneuse in a medical context. Smartphones and any specific app used in cervical cancer screening programs are considered medical devices. The WHO considers medical devices as "indispensable to advance universal health coverage, address health emergencies, and promote healthier populations"; and most countries have regulatory controls and regional guidelines for the correct use of medical devices and mHealth data. As in every study protocol approved by an ethics committee, patients' agreement is necessary for the use of personal data.

Smartphone D-VIA is a promising tool used to improve the quality and efficiency of cervical visual assessment in low resource settings and in remote areas; therefore, helping clinicians in the diagnosis of pre-cancerous lesions [17]. Images can be stored in a VIA image bank and be used for training; sharing real-time images with long-distance experts will improve the quality of work of healthcare providers. Although the evidence supports that D-VIA improves CIN2+ diagnostic performance, the use of smartphone applications is only considered as a tool to minimize the subjectivity of the diagnosis. The use of mHealth applications is on the rise and might improve and facilitate cervical cancer screening by guiding healthcare workers through a decision-making algorithm, independent of the level of experience. In the future, a computer-assisted automated visual evaluation will be able to discriminate between normal and CIN and will likely significantly improve diagnostic accuracies, as well as allow see-and-treat approaches.

LMIC healthcare providers should focus on the implementation and development of smartphone-based screening programs using D-VIA, as it is proven to be acceptable and inexpensive, and it aligns with the WHO's effort towards elimination of cervical cancer in the twenty-first century. Rossman et al. published a systematic review on the use of 
digital health strategies for CC control in LMICs, showing that most interventions focused on secondary prevention [47]. Strategies are used to "facilitate patient education, digital cervicography, health worker training, and data quality", but the evidence for effectiveness is limited and comes under a lot of bias. A meta-analysis could not be conducted because of the lack of matched outcomes between studies, which support the need to conduct further and stronger studies in developing countries.

Author Contributions: Authors contributions: Conceptualization, S.L.M. and P.P.; methodology, J.S. and S.L.M.; data analysis, J.S., E.J. and R.V.; original draft preparation, L.S and B.K.; writing, review and editing, J.S., S.L.M., R.V., E.J. and P.P.; supervision, P.V. and P.P.; project administration, J.S. and E.J. All authors have read and agreed to the published version of the manuscript.

Funding: This research received no external funding.

Institutional Review Board Statement: Not applicable.

Informed Consent Statement: Not applicable.

Data Availability Statement: Not applicable.

Conflicts of Interest: The authors declare no conflict of interest.

\section{References}

1. Globocan. Globocan 2020: New Global Cancer Data. Available online: https://www.uicc.org/news/globocan-2020-new-globalcancer-data (accessed on 29 December 2021).

2. World Health Organisation. Global Strategy to Accelerate the Elimination of Cervical Cancer as a Public Health Problem. Available online: https:/ /www.who.int/publications/i/item/9789240014107 (accessed on 29 December 2021).

3. World Health Organisation. Guidelines for Screening and Treatment of Precancerous Lesions for Cervical Cancer Prevention. Available online: http://www.who.int/reproductivehealth/publications / cancers_screening_and_treatment_of_precancerous_ lesions/en/ (accessed on 29 December 2021).

4. Cubie, H.A.; Campbell, C. Cervical cancer screening-The challenges of complete pathways of care in low-income countries: Focus on Malawi. Womens Health 2020, 16, 1745506520914804. [CrossRef] [PubMed]

5. Firnhaber, C.; Mao, L.; Levin, S.; Faesen, M.; Lewis, D.A.; Goeieman, B.J.; Swarts, A.J.; Rakhombe, N.; Michelow, P.M.; Williams, S.; et al. Evaluation of a cervicography-based program to ensure quality of visual inspection of the cervix in HIVinfected women in Johannesburg, South Africa. J. Low. Genit. Tract Dis. 2015, 19, 7-11. [CrossRef] [PubMed]

6. Manga, S.; Parham, G.; Benjamin, N.; Nulah, K.; Sheldon, L.K.; Welty, E.; Ogembo, J.G.; Bradford, L.; Sando, Z.; Shields, R.; et al. Cervical cancer screening in cameroon: Interobserver agreement on the interpretation of digital cervicography results. J. Low. Genit. Tract Dis. 2015, 19, 288-294. [CrossRef] [PubMed]

7. Sankaranarayanan, R.; Budukh, A.M.; Rajkumar, R. Effective screening programmes for cervical cancer in low-And middleincome developing countries. Bull. World Health Organ. 2001, 79, 954-962. [PubMed]

8. Goel, A.; Gandhi, G.; Batra, S.; Bhambhani, S.; Zutshi, V.; Sachdeva, P. Visual inspection of the cervix with acetic acid for cervical intraepithelial lesions. Int. J. Gynaecol. Obstet. 2005, 88, 25-30. [CrossRef] [PubMed]

9. Mustafa, R.A.; Santesso, N.; Khatib, R.; Mustafa, A.A.; Wiercioch, W.; Kehar, R.; Gandhi, S.; Chen, Y.; Cheung, A.; Hopkins, J.; et al Systematic reviews and meta-analyses of the accuracy of HPV tests, visual inspection with acetic acid, cytology, and colposcopy. Int. J. Gynaecol. Obstet. 2016, 132, 259-265. [CrossRef] [PubMed]

10. World Health Organisation. Control of cancer of the cervix uteri. A WHO meeting. Bull World Health Organ 1986, 64, 607-618.

11. World Health Organisation. Comprehensive Cervical Cancer Control: A Guide to Essential Practice-Second Edition. Available online: https:/ / www.who.int/reproductivehealth/publications/cancers/cervical-cancer-guide/en/ (accessed on 29 December 2021).

12. Parham, G.P.; Mwanahamuntu, M.H.; Pfaendler, K.S.; Sahasrabuddhe, V.V.; Myung, D.; Mkumba, G.; Kapambwe, S.; Mwanza, B.; Chibwesha, C.; Hicks, M.L.; et al. eC3-A modern telecommunications matrix for cervical cancer prevention in Zambia. J. Low. Genit. Tract. Dis. 2010, 14, 167-173. [CrossRef] [PubMed]

13. de Castro Hillmann, E.; Moreira Bacha, O.; Roy, M.; Paris, G.; Berbiche, D.; Nizard, V.; Lopes Ramos, J.G. Cervical Digital Photography: An Alternative Method to Colposcopy. J. Obstet. Gynaecol. Can. 2019, 41, 1099-1107. [CrossRef]

14. De Vuyst, H.; Claeys, P.; Njiru, S.; Muchiri, L.; Steyaert, S.; De Sutter, P.; Van Marck, E.; Bwayo, J.; Temmerman, M. Comparison of pap smear, visual inspection with acetic acid, human papillomavirus DNA-PCR testing and cervicography. Int. J. Gynaecol. Obstet. 2005, 89, 120-126. [CrossRef] [PubMed]

15. Bateman, A.C.; Katundu, K.; Mwanahamuntu, M.H.; Kapambwe, S.; Sahasrabuddhe, V.V.; Hicks, M.L.; Chi, B.H.; Stringer, J.S.; Parham, G.P.; Chibwesha, C.J. The burden of cervical pre-cancer and cancer in HIV positive women in Zambia: A modeling study. BMC Cancer 2015, 15, 541. [CrossRef] 
16. Ricard-Gauthier, D.; Wisniak, A.; Catarino, R.; van Rossum, A.F.; Meyer-Hamme, U.; Negulescu, R.; Scaringella, S.; Jinoro, J.; Vassilakos, P.; Petignat, P. Use of smartphones as adjuvant tools for cervical cancer screening in low-resource settings. J. Low. Genit. Tract Dis. 2015, 19, 295-300. [CrossRef] [PubMed]

17. Gallay, C.; Girardet, A.; Viviano, M.; Catarino, R.; Benski, A.C.; Tran, P.L.; Ecabert, C.; Thiran, J.P.; Vassilakos, P.; Petignat, P. Cervical cancer screening in low-resource settings: A smartphone image application as an alternative to colposcopy. Int. J. Womens Health 2017, 9, 455-461. [CrossRef] [PubMed]

18. Tran, P.L.; Benski, C.; Viviano, M.; Petignat, P.; Combescure, C.; Jinoro, J.; Herinianasolo, J.L.; Vassilakos, P. Performance of Smartphone-Based Digital Images for Cervical Cancer Screening in a Low-Resource Context. Int. J. Technol. Assess Health Care 2018, 34, 337-342. [CrossRef] [PubMed]

19. Mungo, C.; Osongo, C.O.; Ambaka, J.; Randa, M.A.; Samba, B.; Ochieng, C.A.; Barker, E.; Guliam, A.; Omoto, J.; Cohen, C.R. Feasibility and Acceptability of Smartphone-Based Cervical Cancer Screening Among HIV-Positive Women in Western Kenya. JCO. Glob. Oncol. 2021, 7, 686-693. [CrossRef]

20. Goldstein, A.; Goldstein, L.S.; Lipson, R.; Bedell, S.; Wang, J.; Stamper, S.A.; Brenner, G.; Goldstein, G.R.; O’Keefe, K.D.; $\mathrm{O}^{\prime}$ Keefe, S.C.; et al. Assessing the feasibility of a rapid, high-volume cervical cancer screening programme using HPV selfsampling and digital colposcopy in rural regions of Yunnan, China. BMJ Open 2020, 10, e035153. [CrossRef]

21. Thay, S.; Goldstein, A.; Goldstein, L.S.; Govind, V.; Lim, K.; Seang, C. Prospective cohort study examining cervical cancer screening methods in HIV-positive and HIV-negative Cambodian Women: A comparison of human papilloma virus testing, visualization with acetic acid and digital colposcopy. BMJ Open 2019, 9, e26887. [CrossRef]

22. Urner, E.; Delavy, M.; Catarino, R.; Viviano, M.; Meyer-Hamme, U.; Benski, A.C.; Jinoro, J.; Heriniainasolo, J.L.; Undurraga, M.; De Vuyst, H.; et al. A Smartphone-based approach for triage of human papillomavirus-positive sub-saharan african women: A prospective study. JMIR Mhealth Uhealth 2017, 5, e72. [CrossRef]

23. Catarino, R.; Vassilakos, P.; Scaringella, S.; Undurraga-Malinverno, M.; Meyer-Hamme, U.; Ricard-Gauthier, D.; Matute, J.C.; Petignat, P. Smartphone Use for Cervical Cancer Screening in Low-Resource Countries: A Pilot Study Conducted in Madagascar. PLoS ONE 2015, 10, e0134309. [CrossRef]

24. Silkensen, S.L.; Schiffman, M.; Sahasrabuddhe, V.; Flanigan, J.S. Is It Time to Move Beyond Visual Inspection With Acetic Acid for Cervical Cancer Screening? Glob. Health Sci. Pract. 2018, 6, 242-246. [CrossRef]

25. Asgary, R.; Cole, H.; Adongo, P.; Nwameme, A.; Maya, E.; Adu-Amankwah, A.; Barnett, H.; Adanu, R. Acceptability and implementation challenges of smartphone-based training of community health nurses for visual inspection with acetic acid in Ghana: mHealth and cervical cancer screening. BMJ Open 2019, 9, e030528. [CrossRef] [PubMed]

26. Yeates, K.E.; Sleeth, J.; Hopman, W.; Ginsburg, O.; Heus, K.; Andrews, L.; Giattas, M.R.; Yuma, S.; Macheku, G.; Msuya, A.; et al. Evaluation of a Smartphone-Based Training Strategy Among Health Care Workers Screening for Cervical Cancer in Northern Tanzania: The Kilimanjaro Method. J. Glob. Oncol. 2016, 2, 356-364. [CrossRef] [PubMed]

27. Negulescu, R.A.; Catarino, R.; De Vuyst, H.; Undurraga-Malinverno, M.; Meyer-Hamme, U.; Alec, M.; Campana, A.; Vassilakos, P.; Petignat, P. Web-based instrument to assess skills in visual inspection of the cervix among healthcare providers. Int. J. Gynaecol. Obstet. 2016, 134, 107-113. [CrossRef] [PubMed]

28. Sanghvi, H.; Limpaphayom, K.K.; Plotkin, M.; Charurat, E.; Kleine, A.; Lu, E.; Eamratsameekool, W.; Palanuwong, B. Cervical cancer screening using visual inspection with acetic acid: Operational experiences from Ghana and Thailand. Reprod Health Matters 2008, 16, 67-77. [CrossRef]

29. Asgary, R.; Staderini, N.; Mthethwa-Hleta, S.; Lopez Saavedra, P.A.; Garcia Abrego, L.; Rusch, B.; Marie Luce, T.; Rusike Pasipamire, L.; Ndlangamandla, M.; Beideck, E.; et al. Evaluating smartphone strategies for reliability, reproducibility, and quality of VIA for cervical cancer screening in the Shiselweni region of Eswatini: A cohort study. PLoS Med. 2020, 17, e1003378. [CrossRef]

30. Yeates, K.; Erwin, E.; Mtema, Z.; Magoti, F.; Nkumbugwa, S.; Yuma, S.; Hopman, W.M.; Ferguson, A.; Oneko, O.; Macheku, G.; et al. Smartphone-Enhanced Training, QA, Monitoring, and Evaluation of a Platform for Secondary Prevention of Cervical Cancer: Opportunities and Challenges to Implementation in Tanzania. JCO Glob. Oncol. 2020, 6, 1114-1123. [CrossRef]

31. Quercia, K.; Tran, P.L.; Jinoro, J.; Herniainasolo, J.L.; Viviano, M.; Vassilakos, P.; Benski, C.; Petignat, P. A Mobile Health Data Collection System for Remote Areas to Monitor Women Participating in a Cervical Cancer Screening Campaign. Telemed. J. E. Health 2018, 24, 277-282. [CrossRef]

32. Sharma, D.; Rohilla, L.; Bagga, R.; Srinivasan, R.; Jindal, H.A.; Sharma, N.; Kankaria, A.; Jamir, L.; Suri, V.; Singh, R.K.; et al Feasibility of implementing cervical cancer screening program using smartphone imaging as a training aid for nurses in rural India. Public Health Nurs. 2018, 35, 526-533. [CrossRef]

33. Asgary, R.; Adongo, P.B.; Nwameme, A.; Cole, H.V.; Maya, E.; Liu, M.; Yeates, K.; Adanu, R.; Ogedegbe, O. mHealth to Train Community Health Nurses in Visual Inspection With Acetic Acid for Cervical Cancer Screening in Ghana. J. Low Genit. Tract. Dis. 2016, 20, 239-242. [CrossRef]

34. Peterson, C.W.; Rose, D.; Mink, J.; Levitz, D. Real-Time Monitoring and Evaluation of a Visual-Based Cervical Cancer Screening Program Using a Decision Support Job Aid. Diagnostics 2016, 6, 20. [CrossRef] 
35. Fokom Domgue, J.; Baker, E.; Manjuh, F.; Lopez, M.; Welty, T.; Schmeler, K.M.; The Cameroon Cervical Cancer Prevention ECHO Collaborative Group. Connecting frontline providers in Africa with distant experts to improve patients' outcomes through Project ECHO: A successful experience in Cameroon. Int. J. Gynecol. Cancer 2019, 29, 1446-1447. [CrossRef] [PubMed]

36. Bhatt, S.; Isaac, R.; Finkel, M.; Evans, J.; Grant, L.; Paul, B.; Weller, D. Mobile technology and cancer screening: Lessons from rural India. J. Glob. Health 2018, 8. [CrossRef] [PubMed]

37. Fink, C.; Blum, A.; Buhl, T.; Mitteldorf, C.; Hofmann-Wellenhof, R.; Deinlein, T.; Stolz, W.; Trennheuser, L.; Cussigh, C.; Deltgen, D.; et al. Diagnostic performance of a deep learning convolutional neural network in the differentiation of combined naevi and melanomas. J. Eur. Acad. Dermatol. Venereol. 2020, 34, 1355-1361. [CrossRef] [PubMed]

38. Aggarwal, R.; Sounderajah, V.; Martin, G.; Ting, D.S.W.; Karthikesalingam, A.; King, D.; Ashrafian, H.; Darzi, A. Diagnostic accuracy of deep learning in medical imaging: A systematic review and meta-analysis. NPJ Digit. Med. 2021, 4, 65. [CrossRef]

39. Miyagi, Y.; Takehara, K.; Miyake, T. Application of deep learning to the classification of uterine cervical squamous epithelial lesion from colposcopy images. Mol. Clin. Oncol. 2019, 11, 583-589. [CrossRef]

40. Xue, P.; Tang, C.; Li, Q.; Li, Y.; Shen, Y.; Zhao, Y.; Chen, J.; Wu, J.; Li, L.; Wang, W.; et al. Development and validation of an artificial intelligence system for grading colposcopic impressions and guiding biopsies. BMC Med. 2020, 18, 406. [CrossRef]

41. Peng, G.; Dong, H.; Liang, T.; Li, L.; Liu, J. Diagnosis of cervical precancerous lesions based on multimodal feature changes. Comput. Biol. Med. 2021, 130, 104209. [CrossRef]

42. Li, Y.; Liu, Z.H.; Xue, P.; Chen, J.; Ma, K.; Qian, T.; Zheng, Y.; Qiao, Y.L. GRAND: A large-scale dataset and benchmark for cervical intraepithelial Neoplasia grading with fine-grained lesion description. Med. Image. Anal. 2021, 70, 102006. [CrossRef]

43. Xue, Z.; Novetsky, A.P.; Einstein, M.H.; Marcus, J.Z.; Befano, B.; Guo, P.; Demarco, M.; Wentzensen, N.; Long, L.R.; Schiffman, M.; et al. A demonstration of automated visual evaluation of cervical images taken with a smartphone camera. Int. J. Cancer 2020, 147, 2416-2423. [CrossRef]

44. Kudva, V.; Prasad, K.; Guruvare, S. Andriod Device-Based Cervical Cancer Screening for Resource-Poor Settings. J. Digit Imaging 2018, 31, 646-654. [CrossRef]

45. Bae, J.K.; Roh, H.J.; You, J.S.; Kim, K.; Ahn, Y.; Askaruly, S.; Park, K.; Yang, H.; Jang, G.J.; Moon, K.H.; et al. Quantitative Screening of Cervical Cancers for Low-Resource Settings: Pilot Study of Smartphone-Based Endoscopic Visual Inspection After Acetic Acid Using Machine Learning Techniques. JMIR Mhealth Uhealth 2020, 8, e16467. [CrossRef] [PubMed]

46. Vinals, R.; Vassilakos, P.; Rad, M.S.; Undurraga, M.; Petignat, P.; Thiran, J.P. Using dynamic features for automatic cervical precancer detection. Diagnostics 2021, 11, 716. [CrossRef] [PubMed]

47. Rossman, A.H.; Reid, H.W.; Pieters, M.M.; Mizelle, C.; von Isenburg, M.; Ramanujam, N.; Huchko, M.J.; Vasudevan, L. Digital Health Strategies for Cervical Cancer Control in Low- and Middle-Income Countries: Systematic Review of Current Implementations and Gaps in Research. J. Med. Internet Res. 2021, 23, e23350. [CrossRef] [PubMed] 